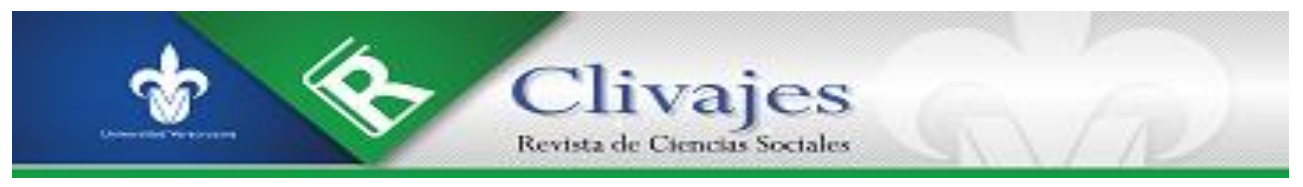

Leopoldo Alafita Méndez

MARGARITA URÍAS HERMOSILLO. OBRA HISTÓRICA

Clivajes. Revista de Ciencias Sociales. Año V, número 10, julio diciembre 2018, pp. 123-132.

http://clivajes.uv.mx/index.php/Clivajes/article/view/2554/4436

Instituto de Investigaciones Histórico-Sociales, Universidad Veracruzana

Clivajes. Revista de Ciencias Sociales/ISSN: 2395-9495/IIH-S, UV/Xalapa, Veracruz, México.

Recibido: 04-09-2018

Aceptado: 10/09/2018

Publicación: 08/12/2018

Clivajes. Revista de Ciencias Sociales (ISSN: 2395-9495), Año V, Núm. 10, julio-diciembre, 2018 


\section{MARGARITA URÍAS HERMOSILLO. OBRA HISTÓRICA}

\author{
Leopoldo Alafita Méndez \\ IIH-S, Universidad Veracruzana
}

Parece que no hace tanto tiempo que Margarita llegó a Xalapa con Emiliano y la guitarra con la cual cantaba Qué bonita bandera. La intrépida Margarita por circunstancias de las instituciones, muy pronto en su vida estaría encargada de la dirección del Centro de Estudios Históricos: en un abrir y cerrar de ojos, se convirtió en líder de un grupo de estudiantes de distintos orígenes geográficos y académicos, con quienes planteaba nuevos enfoques para revelar nuevos sujetos de investigación, cercanos al compromiso con las clases subalternas, donde los movimientos sociales ocuparían espacios privilegiados y sobre los que se induciría la realización de seminarios, conferencias, talleres y encuentros académicos.

Con Margarita en el Centro, se privilegió la búsqueda de fuentes de información histórica de Veracruz. Muchos de los caminos que se recorren actualmente merecieron discusiones de estudio en favor de lecturas fundadas en preguntas desde el presente de entonces y talleres teóricos que hacían sentido a las preocupaciones de investigación. Escuelas históricas e historiografía fueron parte de una incesante actividad. De los seminarios surgieron intereses de investigación sobre el movimiento sindical de Veracruz, los movimientos por la tierra y la organización de los campesinos del Estado.

En la introducción a Margarita Urías Hermosillo. Obra histórica, publicada por la Universidad Veracruzana, José González Sierra detalla estas actividades que formaron de manera comprometida la primera fase de la vida del Centro. En buena medida, debemos a Margarita el desenfado ante el modo de ser académico, un sello que no aceptó: no toleraba que los académicos o los estudiantes miraran por encima del hombro.

En el primer ensayo del libro, "Regionalismo Cultural en Juárez", Margarita permite atisbar un complejo urbano que más adelante iba a ser motivo de muy interesantes estudios desde varios ángulos de las ciencias, y que tocan temas inaugurados por la autora. Su estudio nos introduce en un tiempo de la ciudad que estará después en la atención sociológica de muchos investigadores. "Regionalismo Cultural en Juárez" permite captar la sensibilidad de Margarita Urías para seleccionar e ir a la problemática de sus objetos de indagación. 
En su trayectoria de investigación, la autora se aproximó a la historia reciente de Puebla en el periodo del dominio caciquil de Ávila Camacho, desde su desarrollo hasta la decadencia; estudió la integración de fuerzas sociales del poder regional en la sierra norte de Puebla, desde la alta jerarquía poblana productores de café, comerciantes de la vainilla, jefes militares, políticos, empresarios agrícolas, industriales y banqueros; se ocupó de la oligarquía poblana, con sus vínculos nacionales y sus pares del estado de Veracruz, enfatizando, en el control del poder regional, la pacificación de los grupos de trabajadores y el movimiento agrarista, lo cual consolidó relaciones con el alemanismo.

Margarita Urías analizó la consolidación del cacicazgo de Ávila Camacho a medida que, destejía el proyecto nacional cardenista, en la coyuntura del fin de la guerra, rectificando tanto el proyecto de educación pública, como el impulso a dirigentes sindicales comprometidos con el régimen; un asunto de suma trascendencia, pues en ese momento los dirigentes sindicales tenían bajo su control la tarea de mediar en el conflicto. Sin su intervención, hubieran resultado difíciles el desarrollo de programas de gobierno y la propia gobernabilidad. Según Margarita, fue un periodo violento $y$ despótico, de represión a grupos indígenas y al movimiento obrero, que resistía los embates de ese gobierno de derecha. El declive del cacicazgo regional es muy revelador con respecto a la imposición de proyectos políticos que se ajustaron a determinados momentos económicos y de poder durante el régimen de Díaz Ordaz y Luis Echeverría. En la parte final, aborda el importante papel de la iglesia católica en la historia contemporánea de Puebla.

Dada su variedad y riqueza temática, sería deseable que el libro constara en varios índices que permitieran su consulta detallada. Sus aportes sobre la historia de Chihuahua merecen destacarse, quizá en libro impreso, por separado, para que el estudio específico de esa entidad estuviera a disposición de los habitantes, y para hacer más práctica su consulta para los estudiantes.

Otra aportación de Margarita Urías Hermosillo. Obra Histórica es la revisión historiográfica, el acercamiento de la autora a las fuentes. Urías siempre recomendó a sus estudiantes perder el respeto a los intelectuales. En una época en que no existían los estímulos y se trabajaba con otras prioridades, con objetivos distintos, resultaba un verdadero lujo escucharla polemizar con invitados o autores de contexto, e incluso revisar sus planteamientos con nuevas formulaciones para teorizar.

La articulación teórica entre historiografía, Estado-nación y población es una muestra del análisis realizado por Urías acerca de la producción editorial de 
la primera parte del México independiente, una vez instalada la República, relacionando en todo momento autores con personajes en el poder.

La autora emprende una serie de estudios sobre estrategias para superar la crisis económica que agobiaba a la sociedad; estudios que remiten a la organización del sistema productivo nacional o a cómo lograr la reconstrucción del mercado interno y el mercado crediticio. Así, la autora destaca el trabajo de Michael Casteloe sobre la primera República (México, 1824), revisando y situando los estudios en una categoría a la que clasifica como "ideología de desarrollo", en donde resalta la preocupación por la realidad preindustrial, lo que conlleva formular proyectos y modelos de desarrollo industrial; de ahí que la industria textil fuera lo viable, cuando las necesidades básicas eran vestimenta, alimentación y vivienda, siguiendo el modelo de las potencias europeas; pero tal proyecto no excluía ni a la agricultura ni a la minería. Ahí destacaron Lucas Alamán y Esteban Antuñano.

Un referente obligado de Margarita Urías es José María Luis Mora cuyos postulados cuestionaron los argumentos de autores que se identificaron con los principios pro industrialización; él veía con mayor viabilidad proyectos relacionados con la agricultura y la minería. La mano de obra era uno de los límites para la industrialización, lo que ocasionaría el desmantelamiento de los trabajos en la agricultura y la minería. Para Mora, el modelo era el desarrollo agrícola norteamericano. Situó la discusión en torno de un modelo económico que no sólo modificó la intervención gubernamental, sino también el destino de regímenes liberales, con los que se reconvertía a los pueblos y su cultura. La tradición se alteró, enfrentando a los poderes coloniales, el papel de la iglesia y de la milicia. Librecambio y desarrollo económico se volvieron banderas que desembocaron en el movimiento de Reforma y fueron el cuerpo ideológico de ese periodo histórico. El estudio de Urías recorre la industrialización textil y analiza la folletería que se produjo antes del medio siglo XIX.

Con Manuel Payno en Hacienda, se instrumentaron políticas liberales que propiciaron medidas contra la protección de los textiles, siendo la consolidación del Estado liberal moderno lo que apagó finalmente la voz de los fabricantes, según Margarita Urías. Las políticas dirigidas al campo realmente estuvieron encaminadas a propietarios que concentraban tierras y se ubicaban en las cercanías de la Ciudad de México, centro del país, y en las costas de Veracruz. Estos temas fueron abordados por David Brading, cuya investigación revisó Urías con 
detenimiento, al tiempo que leía a Lucas Alamán. En cuanto a comercio exterior, Lerdo de Tejada fue muy sistemático en sus series de información estadística; información sumamente útil para legislar sobre comercio hacia la segunda parte del XIX. Estas fuentes económicas y la normatividad surgida de la legislación fueron prueba fehaciente de la constitución de un campo importante para la construcción del Estado.

Los intereses comerciales crecieron desde el surgimiento de los proyectos para construir el Ferrocarril del Istmo. Así se vincularon capitales interesados en encauzar la comunicación interoceánica, involucrando comerciantes y empresarios nacionales y extranjeros, principalmente norteamericanos. Los trabajos de Margarita Urías también contemplaron las funciones bancarias de las casas comerciales de cambio, interno y externo, de ahorro de sectores medios y hasta de artesanos. Así se invirtió en ferrocarriles, en grandes fincas urbanas y rurales; se compraron bienes desamortizados y se aventuraron a nuevas regiones; entraron en nuevos deslindes, terrenos baldíos, y se colocaron capitales en bancos europeos y norteamericanos.

En Margarita Urías. Obra histórica, este apartado historiográfico cierra con la creación de la Sociedad Mexicana de Geografía y Estadística, el Ministerio de Fomento y la Dirección de Colonización e Industria, así como de las Juntas que le precedieron y el Ministerio de Hacienda, instituciones responsables de la publicación y difusión de las memorias de los estados. De acuerdo con la autora, gran parte de la información cualitativa y cuantitativa de mayor riqueza quedó impresa en periódicos y folletos, por lo que advierte sobre la importancia de su consulta para introducir modificaciones sustanciales de su interpretación.

De los autores contemporáneos de la historiografía económica, surgidos durante el porfiriato, Urías destaca a Justo Sierra y sus conceptos spencerianos de desarrollo espontáneo, entre otros autores inspirados en la psicología social, los más numerosos seguidores de la concepción comtiana positivista que ordenaba a la sociedad bajo el poder político y el poder natural, es decir, a los científicos y los industriales. En ese tenor, en su revisión desfilan Genaro Raigosa, Carlos Díaz Dufoo, Pablo Macedo y Gilberto Crespo y Martínez. El objeto de estos autores, según Margarita Urías, era crear un cuerpo orgánico de la historia oficial del país que justificara el régimen de dominio de la clase que representaban. En su opinión, esta obra de los científicos cumplió satisfactoriamente la tarea que se proponían. Como corriente de pensamiento, el método positivista fue $-\mathrm{y}$ más allá del periodo positivista siguió siendo- un modelo para analizar a la sociedad, con un tipo de interpretación condicionado por el manejo de sus propios instrumentos analíticos. 
PROBlemas DEL DESARROLlO DEL CAPITALISMO EN MÉXICO EN LA OBRA HISTÓRICA DE URÍAS

La Revolución Mexicana es el fin de la hacienda como unidad económica rural, del dominio de los científicos en el poder, y el suceso que marca el predominio urbano industrial: este apartado aborda las relaciones entre el Estado oligárquico y la sociedad, mediadas por una relación de exclusión creciente. El vacío de poder que se instala, a la caída del régimen, permitió un rejuego entre las clases de las que surge un Estado desarticulado que tuvo que permitir, en su sobrevivencia, la apertura al desarrollo capitalista así como la creación de empleos. Se hicieron necesarias reformas que confirmaran la supresión de relaciones con los grupos oligárquicos. Las políticas y programas que permitieron ese deslinde se desarrollaron con la construcción de carreteras y presas hidroeléctricas. Así surgió una de las características de un Estado que monopoliza y hegemoniza las condiciones para que el capital se desarrolle con su concurso y control. Como lo demuestra Margarita Urías, eso permitió integrar rápidamente a amplios grupos sociales desde una perspectiva autoritaria; incluyente sí, pero autoritaria. Un Estado que se reproduce desde el reconocimiento y el consenso en toda la estructura social.

En ese modelo de Estado de la Revolución, también jugó un papel de primer orden la Reforma Agraria de los veinte, el cual pasó a incorporar masivamente a otros amplios grupos de la población rural de distintas regiones del país. Así, jugó la estrategia de entregar la pequeña propiedad o entregar tierras a los campesinos desde la Reforma Agraria. Ese desarrollo de empresarios medios en las comunidades además fue un motor del desarrollo del comercio y de la pequeña empresa en la ciudad. Cuanto más se ampliaban el desarrollo del capital y el mercado de la mano de obra, más capas dominadas, "corporativas", incorporaba el Estado al aparato político, lo que aseguraba su propia reproducción $\mathrm{y}$, al mismo tiempo, la integración nacional.

\section{EMPRESARIOS MEXICANOS DEL SIGLO XIX Y} EL CASO ESCANDÓN

Esta serie de estudios, que debería ser analizada para su probable publicación en dos libros impresos, es una de las preocupaciones de investigación escrita con negritas en la Obra histórica de Margarita Urías. Abarca la participación económica y empresarial del grupo Escandón en la formación económica mexicana, a partir de actividades comerciales de importación-exportación y abastecimiento. De acuerdo con Urías, como empresario ferroviario es como Escandón logra acumular la parte fundamental de sus ingresos. La historia empresarial de este personaje encierra de 
manera importante la historia del país, de los procesos económicos del desarrollo social y laboral, así como del papel que sus recursos naturales han jugado para los grupos de poder y el mercado internacional, pero también del lugar en la historia de una sociedad regional y de Veracruz en particular.

La investigación de Urías abreva de una amplia cantidad de fuentes. Al no disponer entonces de libros o archivos privados, fuentes gubernamentales como el Archivo General de la Nación y el Archivo General de Notarías fueron fundamentales para su primer diseño de investigación; a éstas se sumaron los Archivos de la Compañía de Minas de Real Monte y de Pachuca, de la Secretaria del Patrimonio Nacional. Documentos organizados por Inés Herrera, William Meyers y Cuauhtémoc Velasco, del Departamento de Investigaciones Históricas y del Instituto Nacional de Antropología e Historia.

La familia, el tabaco y los ingenios de la región fueron herencias que llegaron a los Escandón por la vía Garmendia, la vía materna, pero Escandón le dio a estos recursos y a su valor de futuro, dimensiones financieras y especulativas que diversificaron su capital. La autora lo presenta como un organizador en diferentes frentes económicos, que se dio a la tarea de transformar sistemas de trabajo y tecnologías en minería e ingenios azucareros. Promovió también el desarrollo de las vías de comunicación: caminos, carreteras y ferrocarriles. Sus empresas realizaron el deslinde de tierras en el norte, concesiones y riquezas minerales en Chihuahua, Sonora y Sinaloa, y participó en la explotación de minas de sal y azogue en Baja California Norte.

La descripción de las correrías de la autora por los archivos constituye un verdadero ejemplo para la formación de investigadores, una ayuda importante en la formación de estudiantes universitarios que se interesan por el pasado y por acercarse al oficio de historiar. Margarita Urías Hermosillo. Obra histórica aporta un ejemplo sobre las fuentes para la investigación de la histórica económica. También da cuenta de indagaciones en documentos del Archivo de Durango en los que se registran los procedimientos para el contrabando de plata amonedada, en pasta o en barras, que salía de la costa pacífica rumbo Cantón o Hong-Kong; tráfico que fue fuente importante de inversiones en la banca, capital financiero e inversiones en bienes raíces de Europa. Sugiere también el retorno de esos capitales a inversiones en vías de comunicación, como circuitos internacionales desde los recursos mineros coloniales. El circuito explotación de recursos mineros-caminos-ferrocarril, así como la especulación con la deuda pública y los negocios del gobierno aumentaron su importancia con el contrabando de la plata. Plata, opio y tabaco rompieron 
fronteras para ingresar en otros rincones del mundo en la búsqueda de mayores dividendos.

\section{ESCANDÓN. ESTADO. NACIÓN}

Es una revisión de su propia investigación, a la luz de una nueva conceptualización, Urías pone a prueba teorías y métodos de investigación sobre un tema que piensa reconsiderar con un enfoque distinto. Analiza el concepto de "internacionalización" desde la teoría de la dependencia para el estudio de los procesos en términos nacionalistas en su orientación económica. Se refiere a casos de América Latina que ponen de relieve procesos que ocurren y se desenvuelven en el tiempo, como las relaciones entre naciones desigualmente desarrolladas, de donde surgen las características del sistema económico, la división internacional del trabajo, los tráficos comerciales, fianzas y tecnología. Una visión que no daba para analizar otras perspectivas de investigación ni nuevas preguntas a los problemas de las áreas colonizadas o desde los estudios de caso.

Por ejemplo, el de Escandón es un estudio de caso sobre un agente de cambio en una sociedad pluriétnica, escindida en historias regionales y locales, con un Estado en proceso de formación; tales consideraciones estarían fuera del recorte metodológico de la teoría referida. Así, queda fuera de esa visión la relación cultural de convivencia, intercambio, interpenetración y cambio cultural. Reclama el uso conceptual de cambio social desde las dimensiones regionales, nacionales e internacionales, así como los elementos de las ideologías y de la política para organizar y dirigir la economía, la religión, el parentesco, la familia y la cultura. En otras palabras, estamos frente a una propuesta de investigación que asume la antropología en una perspectiva de ciencias sociales, haciendo historia transdisciplinaria. Avanza al proponer que las esferas de la actividad estatal no siempre responden o respaldan, mucho menos conducen, las posibilidades de cambio. La consideración de Gramsci y los intelectuales orgánicos es importante en la reflexión de Margarita Urías para esa parte de la historia comercial y gubernamental de México a finales de la época santanista.

HISTORIOGRAFÍA: LOS HISTORIADORES DEL MOVIMIENTO OBRERO

Un apartado obligado para los historiadores es el acopio historiográfico que realizó Margarita Urías sobre el tema del trabajo y los trabajadores, ejes centrales de su investigación, preponderante durante las primeras dos décadas de vida de este instituto de investigación de la Universidad Veracruzana. Aunque el estudio remite a un mundo académico más amplio en 
temas de investigación sobre los mismos sujetos en otros centros de estudios universitarios del país: BUAP, UNAM, COLMEX, INAH, UAM, etc., con sus referentes internacionales, estudios de caso y reflexiones teóricas, este trabajo revela una intensa actividad de investigación y, a la vez, la construcción colectiva de un discurso liberador de las clases subalternas, de los trabajadores que, pese a las importantes luchas que protagonizaron y de la revolución realizada con su concurso y a su nombre, siguieron sometidos, hasta nuestros días, a condiciones que escapan a sus alcances de protesta y organización.

La relación entre trabajadores y Estado es parte de las preocupaciones de Urías en el acopio historiográfico que recorre su mirada. En sus estudios, observa a una clase cuyas luchas no alteran su condición, pero en las que se explican, en tanto subordinación de las masas, controles desde los actores que los representan, hasta la propia neutralización por parte del Estado, con la intervención de sus agentes o aquellos que se identifican, más claramente, como la nueva derrota de la clase trabajadora.

Un tema destacado por Urías es la generalizada colaboración de las cúpulas que dirigen a los trabajadores, así como las importantes y heroicas victorias de éstos últimos, también transformadoras de su condición social. Rescata los trabajos de Arnaldo Córdoba sobre la acción del
Estado con su política de masas, y el papel del Cardenismo que instrumentó, como mecanismo de Estado, "la dominación corporativa", la cual tuvo reconocimiento y continuidad en los regímenes posteriores. Barry Carr, Adolfo Gilly, Thomson, la conciencia obrera son algunos de los referentes multicitados en los seminarios académicos que también estaban en la formación de las sociedades de socorro mutuo, las organizaciones mutualistas, los anarquistas y el anarcosindicalismo; la protesta, la huelga y los sindicatos de industria. Discusiones de los límites de tiempo actuales, gran generosidad de los participantes, compromiso. Roy Anderson, los obreros y su intervención en la Revolución, la inversión de la fábrica y la clase obrera, activismo y la vida estatutaria.

Industrialización y formación de la clase obrera en Veracruz es un foco de atención en la Obra histórica de Urías. Remite a su estancia en la Universidad Veracruzana y el Instituto de Investigaciones Histórico-Sociales. Detalla problemáticas de los ferrocarriles del Golfo, del Interamericano, el Mexicano, del Ferrocarril del Istmo; los puertos y el desarrollo de los muelles; del desarrollo industrial petrolero, así como de la vieja tradición textil veracruzana. También se ocupa de los ingenios azucareros. Da cuenta de una serie de estudios de la región, centrados en sectores de trabajadores o actores con una gran 
actividad organizativa y rápidas transformaciones. Urías sitúa la historia social como formulación epistemológica. Ese es un punto de llegada, el trabajador en movimiento, pero en su entorno y construyendo. Al final, la autora reflexiona sobre la construcción de comunidades académicas y el trabajo colectivo a los cuales los sistemas de ingeniería y de evaluación dieron al traste en las universidades del país.

Pardo Urías, R. (Comp.) (2017). Margarita Urías Hermosillo. Obra histórica. Xalapa: Universidad Veracruzana [lbook]. 